\title{
Optimization of a wind powered desalination and pumped hydro storage system
}

\section{R. Segurado ${ }^{a, *}$, J.F.A. Madeira ${ }^{a, b}$, M. Costa ${ }^{a}$, N. Duić ${ }^{c}$ and M.G. Carvalho ${ }^{a}$}

${ }^{a}$ IDMEC, Mechanical Engineering Department, Instituto Superior Técnico, Universidade de Lisboa, Lisboa, Portugal

${ }^{\mathrm{b}}$ Department of Mathematics, Instituto Superior de Engenharia de Lisboa, IPL, Rua Conselheiro Emídio Navarro, 1959-007 Lisboa, Portugal

${ }^{\mathrm{c}}$ Department of Energy, Power Engineering and Environment, Faculty of Mechanical Engineering and Naval Architecture, University of Zagreb, Ivana Luč ić a 5, 10002, Zagreb, Croatia

\section{* Corresponding author:}

Raquel Segurado

IDMEC, Mechanical Engineering Department, Instituto Superior Técnico, Av. Rovisco Pais, 1049-001 Lisboa, Portugal

Tel.: + 351218417592; E-mail: raquelsegurado@tecnico.ulisboa.pt 


\section{Abstract}

The penetration of intermittent renewable energy sources, for instances wind power, in the power system of isolated islands is limited, even when there is large potential. The wind power that cannot be directly injected in the power grid is usually curtailed. In addition, some islands need to desalinate seawater to produce fresh water, increasing the pressure on the power system, because desalination needs electricity. Nevertheless, the water scarcity problem of an island can be part of the solution of the problem of its integration of intermittent renewable energy sources. To tackle this issue, a system was proposed to use the excess wind power in desalination units and in a pumped hydro storage, resulting in an integrated power and water supply system that would minimize the wind power curtailed. This paper proposes a methodology to optimize the size and operational strategy of this wind powered desalination and pumped hydro storage system. The objective is to minimize the total annualized production costs, maximize the percentage of renewable energy sources in the total power production and minimize the wind power curtailed. To solve this optimization problem, a derivative free multiobjective optimization method (Direct MultiSearch) is used. This methodology is applied to the integrated power and water supply system proposed for the island of S. Vicente, in Cape Verde. The results show that the penetration of renewable energy sources can reach $84 \%$ with a $27 \%$ decrease of power and water production costs and $67 \%$ decrease of $\mathrm{CO}_{2}$ emissions, in relation to the values foreseen for 2020.

Keywords: Power and water supply; intermittent renewable energy sources integration; desalination; pumped hydro storage; direct multisearch method. 


\section{Introduction}

The penetration of intermittent Renewable Energy Sources (RES), for instances wind power, in the power supply systems of isolated islands depends on the dynamic penetration limit that is usually applied for grid stability (intermittent limit) [1]. This limit is the maximum instantaneous wind power directly supplied to the electricity grid; it is expressed as a percentage of the load and usually it is not higher than 30\% [2]. The excess wind power is the one that cannot be injected in the electricity grid due to that limit. If this wind power is not stored or used to desalinate seawater, it will be curtailed. This study considers the possibility of using the excess wind power to produce fresh water that is stored in a lower reservoir of a Pumped Hydro Storage (PHS) system. The remaining wind power can be stored in this energy storage system.

Erdinc et al. [3] provide an overview of insular power system structures and operational requirements, particularly under increasing penetration of RES. The authors focused on the challenges of these systems and on opportunities to tackle them [3].

A number of studies have been carried out on the feasibility of integrating RES in isolated regions, namely islands, and all of them rely on energy storage and/or demand side management strategies. Kaldellis et al. [4] presents a methodology for the sizing of wind powered PHS systems in the Island of Lesbos, in Greece. This system exploits the excess wind power produced by wind farms, otherwise curtailed due to imposed power grid limitations [4]. In [5], the authors examine the economic viability of this system and find the optimum system configuration, reaching results that are able to increase the RES contribution for the total power production of the island [5].

Katsaprakakis [6] reviews the design and dimensioning of hybrid power plants in autonomous insular power systems of different sizes in Greece, with different technologies for energy generation and storage. The optimization of the dimensioning of the examined 
hybrid power plants is usually based on either the maximization of the RES penetration or on the optimization of economic indices of the required investments [6].

Zhao et al. [7] review the state of the art of the energy storage technologies for wind power integration. The authors conclude that these technologies are an effective solution to handle the reliability and stability challenges of power systems with large scale wind power integration [7].

A number of analyses have been also carried out on the feasibility of using RES in desalination plants [8]. Spyrou et al. [9] investigated the optimum design and operation strategy of a stand-alone reverse osmosis desalination unit powered by wind and solar power and by a PHS unit, capable to fulfil the fresh water demand of areas such as the Greek Islands. The resulting water production costs are very competitive in comparison to the current water transportation prices. The PHS is necessary to guarantee the desired water production throughout the year. The authors conclude that the capacity factors of the power generators are low, while a signification part of the RES production is curtailed, hence they propose the use of the power for other uses in order to increase the capacity factor of the generators and minimize the amount of power curtailed, improving the economic results of the desalination plant.

\subsection{Integrated supply of energy and water}

As seen above, energy and water supply are two types of systems modelled and analysed frequently, but often in a separate way. Most studies focus either on the energy or the water supply system. Some studies consider water as a means of storing energy in a energy supply system (PHS). Moreover, some analyse the energy demand of the water supply system with the use of RES in desalination units. More rarely these two supply systems are analysed together in an integrated way [8]. There is a significant difference between the issues 
concerning the power supply and the water supply. Power production must meet demand at all times, while water can be easy stored. Hence, the studies that analysed the integrated water and power supply in some cases do not consider the water demand curve explicitly, but only determine the amount of water that can be supplied with the system proposed.

Corsini et al. [10] compared a hydrogen based system and a desalinated water production system as two effective alternatives for renewable energy seasonal buffering in an island context (Ventotene Island in Italy). The hourly behaviour of the proposed system is analysed in terms of fuel consumption and hydrogen system energy storage or desalination capacity. The study demonstrates the suitability of both scenarios for the winter renewable energy buffer, in order to improve to the matching of peak energy and water demands [10].

Henderson et al. [11] studied the feasibility of a wind diesel hybrid system that also includes a desalination system component, on Star Island, in New Hampshire, in the United States. The proposed system aimed to supply electricity during the peak demand summer months and to balance the seasonal mismatch between wind resource and electricity demand load via the production and storage of potable water during winter months. Although this study concludes that it is better, from an economical point of view, to waste wind energy than to install a desalination system, the authors conclude that seawater desalination offers an interesting solution, from a technical point of view, to energy storage or long-term load management for wind diesel hybrid systems [11].

Setiawan et al. [12] analysed a scenario for supplying electricity and fulfilling demand for clean water in remote areas using RES and a diesel generator with a desalination plant as deferrable load. The authors simulate the performance of the proposed system in a remote area in the Maldives with about 300 inhabitants and concluded that the proposed system is economically and environmentally viable [12]. 
Novosel et al. [13] proposed a combination of desalination, pump storage that use the produced brine and RES to tackle the issue of water scarcity in Jordan. The results demonstrate that an increase of the flexibility of the desalination units and the use of the brine operated PHS system greatly benefit the reduction of excess RES, increasing the penetration of wind and solar power and water availability [13].

The effects of large scale desalination on the Jordanian energy system was analysed by Østergaard et al. [14], with a particular focus on the large scale introduction of wind power into the energy system. The authors use desalination to decrease excess electricity production and conclude that water storage has some implication on the system's ability to integrate wind power [14].

Santhosh et al. [15] addressed the issue of coupling the infrastructure systems that deliver energy and water by focusing on the supply side of this integrated engineering system, developing a multi-plant real-time simultaneous economic dispatch of power and water. In this analysis, the production costs are minimized subjected to capacity, demand and process constraints. The authors demonstrated that the coproduction minimum capacity limits and process constraints can lead to scenarios where the dispatch can chose the multi-plant instead of the cheaper single product plants. Such results suggest that water and/or power storage can have an important role in reducing process constraints and reducing costs [15].

Bognar et al. [16] analysed the effects of integrating desalination into an island grid with a high share of renewable energies. The authors present options to include a desalination unit into an optimized wind diesel energy supply system for the Island of Brava, in Cabo Verde. Different scenarios were analysed and simulated using hourly data. The authors conclude that the scenario that could provide the lowest and most stable electricity and water costs considering the increasing oil prices is the one that considers the electricity and water production with a discontinuously operating desalination plant. These results show that 
energy supply systems with a high wind power share can benefit from deferrable loads like a variable desalination plant [16].

From the examples mentioned, it is clear that the integrated planning of energy and water supply is crucial to tackle some of the problems arid islands face in the providing quality power and water to their population.

\subsection{Optimization of renewable energy systems}

Optimization methods play a crucial role in the design, planning and control of renewable energy systems. Baños et al. [17] presents a review of the current state of the art in computational optimization methods applied to renewable and sustainable energy. It concludes that the research that uses optimization methods to solve renewable energy problems has increased dramatically in recent years, especially for wind and solar energy systems [17].

According to Østergaard [18], many different optimisation criteria might be applied to the design of renewable energy systems and no unequivocal answer can be found to the question of how to design an optimal energy system. At a general level, renewable energy systems may be designed from an economic perspective or from a techno-operational perspective. Economic optimisations criteria include total energy systems costs, capacity costs and societal costs. From a techno-operational perspective, optimisation criteria include fuel savings, greenhouse gases emissions, elimination of excess power generation, etc. All of these criteria can be applied to assess how well the system integrates renewable energy [18].

Petruschke et al. [19] distinguish between two types of approaches widely followed in designing RES systems: heuristic approaches and optimization-based approaches. Heuristic approaches typically rely on specific expert knowledge or physical insights to define possible energy systems and analyze them in simulation studies. On one hand, this type of approach is 
usually robust and generates solutions with manageable effort, but, on the other hand, only a limited number of alternatives can be studied in simulation studies and the risk to overlook superior solutions is high. In contrast, optimization-based approaches allow the investigation of a practically unlimited number of alternatives and thus generally enable to find the optimal solution among all possible alternatives. However, for large problems the modelling effort and solution times can become prohibitively large. Petruschke proposes a combination of these two approaches [19]. For each approach, there are three levels in designing RES energy systems: configuration level, where technology and equipment choices are made, the sizing level where the equipment capacities are estimated and, the operational level where the operational strategies of the system are specified [19].

\subsection{Multiobjective optimization of renewable energy systems}

Zhou et al. [20] tackle the issue of design, control and optimization of hybrid systems with RES and conclude that it is typical to have conflicting objectives when designing this type of systems, for that it is necessary to use an optimization technique that allows a multiobjective design. Multiobjective approaches are usually divided into: aggregate weight functions and Pareto-based optimization methods [17]. The Pareto-based multiobjective optimization has the advantage of not having the need to adjust the relative weight of each objective to optimize, establishing relationships between solutions according to the Pareto-dominance concept, and facilitating the decision-making process [17].

Anagnostopoulos et al. [21] present a numerical methodology for optimum sizing of the various components of a pumped hydro system designed to recover the wind power rejected in the Island of Crete, in Greece. The results show that a well optimized design is crucial for the technical and economic viability of this system [21]. 
Ren et al. [22] developed a multiobjective optimization model to analyse the optimal operating strategy of a distributed energy resource system, in order to meet the local energy demands while considering both economic and environmental objectives [22].

Sharafi and EIMekkawy [23] present a dynamic multiobjective particle swarm optimization method for the optimal design of hybrid renewable energy systems. The main goal of the design is to minimize simultaneously the total net present cost of the system, unmet load, and carbon dioxide emissions [23].

Perera et al. [24] carried out a multiobjective optimization in order to support decisionmaking for hybrid energy systems in standalone applications. The objective functions were the levelized cost of energy, the initial capital cost and the greenhouse gas emissions. The optimization method used was the Steady $\varepsilon$-State Evolutionary Algorithm, based on the $\varepsilon$ dominance technique [24].

Ma et al. [25] propose a PHS system to increase solar power penetration in a small autonomous system. The genetic algorithm together with Pareto optimality is used for the system techno-economic optimization. The power supply reliability is maximized and the system lifecycle cost is minimized simultaneously [25].

\subsection{Present contribution}

This study addresses a very important issue on the economic, technical and environmental sustainability of the electricity and water supply systems of dry islands.

Most previous research on the energy and water nexus focused on desalination with RES (RES to supply water) or the use of water to produce energy (water to supply energy) and not both of these issues at the same time. The novel aspect of this study is the coupling of these two supply systems in order to increase the integration of intermittent RES and minimize the electricity and water production costs. 
The island of S. Vicente has important wind resources that are not fully used due to its intermittent nature. This island does not have any source of fresh water so all water supplied to the population is desalinated seawater. For this island, Segurado et al. $[8,22]$ proposed an integrated system that uses wind power that cannot be injected in the electricity supply system (excess wind power) to feed the desalination units that produce fresh water, and pumps in a PHS system. Figure 1 presents a scheme of this wind powered desalination and pumped hydro storage system. The power grid of the island is supplied with fossil fuel based units and wind power. This wind power supply has a limitation of $30 \%$ of the hourly load of the power grid (intermittent limit). The excess wind power can be used to supply the desalination plant to produce fresh water and the pump station to transfer this water from the lower reservoir $(L R)$ to the upper reservoir $(U R)$. The fossil fuel based units can also supply the desalination plant. The hydro station can produce power to supply the power grid when water is transferred from the upper reservoir to the lower reservoir.

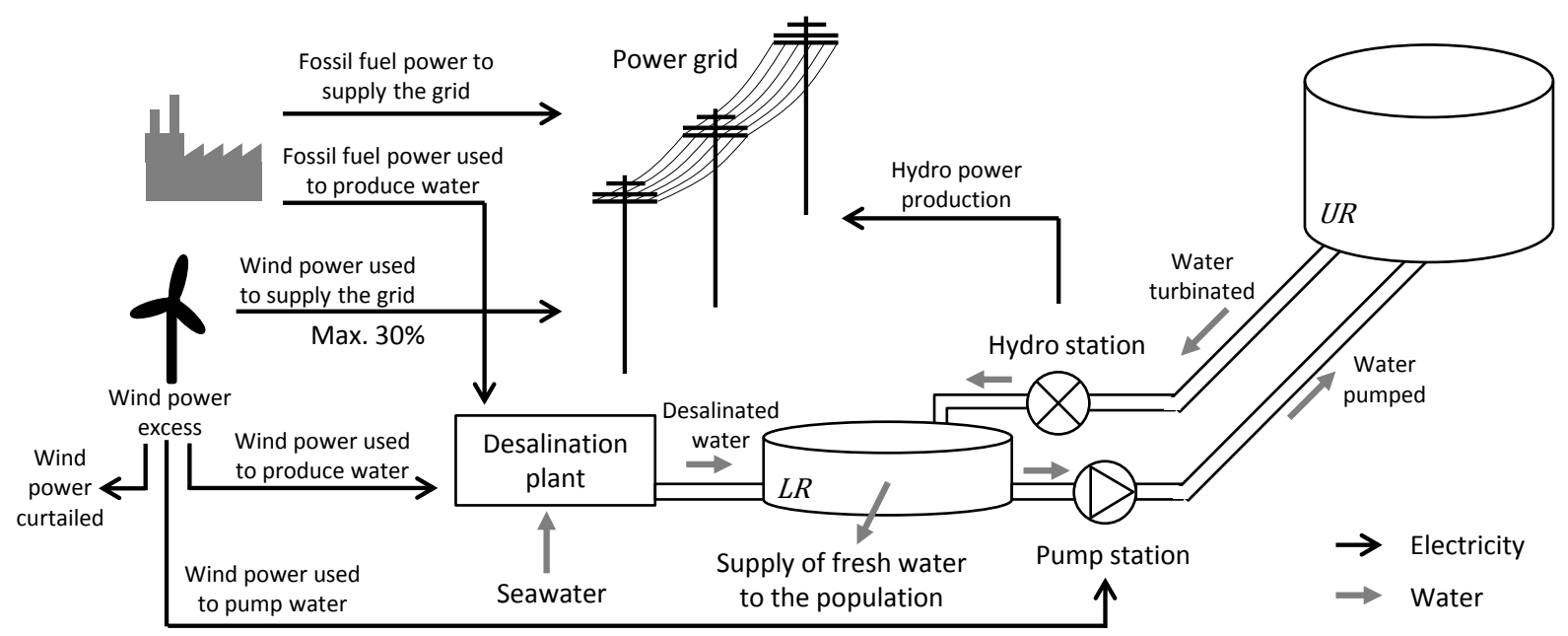

Figure 1. Schematic of the wind powered desalination and pumped hydro storage system.

The present study concentrates on the operational strategy and sizing optimization of this integrated electricity and water supply system so that the total annualized production costs are 
minimized, the percentage of RES in the total power production is maximized and the wind power curtailed is minimized. These three objective functions are determined based on a simulation of the operation of this system; hence, they are discontinuous, non-smooth and not defined in certain points. Therefore, it is necessary to use a multiobjective derivative free method to optimize simultaneously these three, sometimes conflicting, objective functions. To solve this optimization problem, a derivative-free optimization method is used: the Direct MultiSearch (DMS) method. The Pareto optimal set is obtained, from this set several solutions are chosen and analysed in more detail. This optimization method has not been previously used in the area of power and water planning.

\section{Case study}

The case study analysed in this manuscript is the Island of S. Vicente, an island of the Arquipelago of Cape Verde, located about $450 \mathrm{~km}$ of the West African coast. This island had in 2010 about 76,000 inhabitants. S. Vicente has significant problems regarding the power and water supply systems, as the remaining islands of Cape Verde. Cape Verde's power prices are among the highest in Africa due to its dependency on fossil fuel-based plants, which in turn rely on the importation of expensive fuel. Cape Verde has by far the most expensive water tariffs in Africa and among the most expensive in the world. These high prices reflect the water scarcity problem this country faces, where about $85 \%$ of its water production relies on desalination. Moreover, the cost of the energy-intensive desalination process is particularly high due to its dependence on power generation, whose high costs in turn reflect reliance on small-scale diesel generators and expensive imported oil [8]. These problems tend to worsen as it is foreseen an electricity demand of 88,518 MWh for 2020, a $34 \%$ increase in relation to 2012 [8]. 
Currently the power supply system installed in the island has 18.34 MW of thermal fossil fuel-based plants (six different groups with a minimum load of 50\%) and $6.85 \mathrm{MW}$ of wind power. The wind power production potential for one year was estimated in [8] using H2RES and it is about 29,864 MWh. The hourly wind speed values used in this study are from 2005 and were collected from the meteorological station of S. Vicente. A wind speed adjustment is applied using monthly correction factors defined to match wind power production in 2005 . The wind parks in S. Vicente are among the most productive in the world, and the local wind regime is characterized by strong steady winds. For this reason, wind uncertainty is not considered in this study, nevertheless in the implementation phase of this integrated system, it is important to consider the impact of climate change in the wind regimes of the island.

The current water supply system installed in S. Vicente, composed of desalination units with a capacity of $5,400 \mathrm{~m}^{3} /$ day, water distribution system with pumps and a number of reservoirs, it requires about $5 \mathrm{kWh}$ of electricity to produce and supply $1 \mathrm{~m}^{3}$ of water to the population.

In Segurado et al. [8] the baseline scenario for the energy and water supply systems of S. Vicente was modelled in order to compare the results of the proposed system with the current situation in this island. Table 1 presents the share of wind power in the power generation. This power generation refers to the power needed to supply the electricity demand and the desalination units to produce water that is supplied to the population.

Table 1. Power generation in 2020 in the baseline scenario [8].

\begin{tabular}{|l|c|c|}
\hline \multicolumn{1}{|c|}{2020} & \multicolumn{2}{c|}{ Power generation (MWh) } \\
\hline Wind power & 18,966 & $21 \%$ \\
\hline Fossil fuel & 69,552 & $79 \%$ \\
\hline Total & 88,518 & $100 \%$ \\
\hline
\end{tabular}


The wind power curtailed reaches $36 \%$ of the total wind power potential and the total annualized production costs are $28,396,449 €$.

\section{Methods}

The integrated electricity and water supply system proposed for S. Vicente is modelled for the year 2020, taking into account the electricity and water demand forecasted for that year. The sizing and the operational strategy of this system are translated into the variables of the optimization problem.

\subsection{Modelling of the integrated system}

The first step to model this system is to calculate the wind power production potential in each hour of the year, according to the installed wind power considered. This calculation is made using the model used in Segurado et al. [8,26], the H2RES model. Having the wind power production potential $\left(E_{W_{-} P o t_{-} h}\right)$, the load and the water demand for each hour of the year it is possible to calculate the hourly values of:

- Wind power directly injected in the power grid $\left(E_{W_{-} T a k e n_{-} h}-k W h\right)$,

- Undelivered load after the direct supply of wind power $\left(E_{U n d \_L o a d \_h}-k W h\right)$,

- Water produced with wind power $\left(W_{W i n d \_}-m^{3}\right)$,

- Wind power used to produce water $\left(E_{W_{-} \text {Desal_h }}-k W h\right)$,

- Wind power used to pump water $\left(E_{W_{-} P u m p \_}-k W h\right)$,

- Water pumped $\left(W_{P u m p \_h}-m^{3}\right)$,

- Wind power curtailed $\left(E_{C u r t \_}-k W h\right)$,

- Water turbinated - water retrieved from the upper to the lower reservoir, passing through a hydro turbine $\left(W_{\text {Turb } \_h}-m^{3}\right)$,

- Hydro power production $\left(E_{H y d r o \_}-k W h\right)$, 
- Water produced with electricity from the fossil fuel based units $\left(W_{F F_{-} h}-m^{3}\right)$,

- Level of the lower reservoir $\left(n_{L R_{-} h}-m^{3}\right)$,

- Level of the upper reservoir $\left(n_{U R_{-} h}-m^{3}\right)$.

Based on these hourly values it is possible to determine the annual load that is covered by the fossil fuel based units $(\mathrm{kWh})$ and the total annualized production costs of the system $(T C-€)$. For these calculations, it is necessary to estimate the energy needed to pump each unit of water from the lower reservoir to the upper reservoir $-E_{P u m p 1 m^{3}}$, that depends on the height difference of the PHS, the density of water, the acceleration of gravity and on the efficiency of the pumps. An efficiency of $75 \%$ is considered for the pumps [8]. The energy that is possible to produce for each unit of water that goes from the upper to the lower

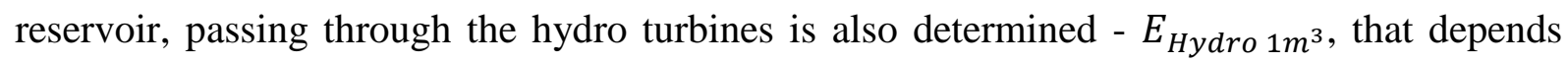
also on the height difference of the PHS, the density of water, the acceleration of gravity and on the efficiency of the hydro turbines. An efficiency of $92 \%$ is considered for the hydro turbines [8]. In order to maximize the exploitation of RES production, the simultaneous operation of the pumps and hydro turbines is allowed.

Figure 2 presents the scheme of the lower reservoir ( $L R$ in Figure 1), as well as the range of the three variables related with the operational levels of the wind powered desalination and PHS system $\left(n_{W B}, n_{H}\right.$, and $\left.n_{F F}\right)$. The variable $n_{W B}$ is the level of the lower reservoir that determines the balance between the excess wind power that is used to desalinate and to pump water to the upper reservoir. This variable ranges from zero to the maximum level of the reservoir $\left(n_{T}\right)$. The variable $n_{H}$ is the level of the lower reservoir in which the hydro production stops. This variable ranges from $n_{0}$, the minimum level of the reservoir, to $n_{T}$. When the level of the lower reservoir is less than $n_{0}$, and it is not possible to turbinate water from the upper reservoir, fossil fuel based units supply the desalination units to produce water 
until the level of the lower reservoir reaches $n_{F F}$. This variable also ranges between $n_{0}$ and $n_{T}$.

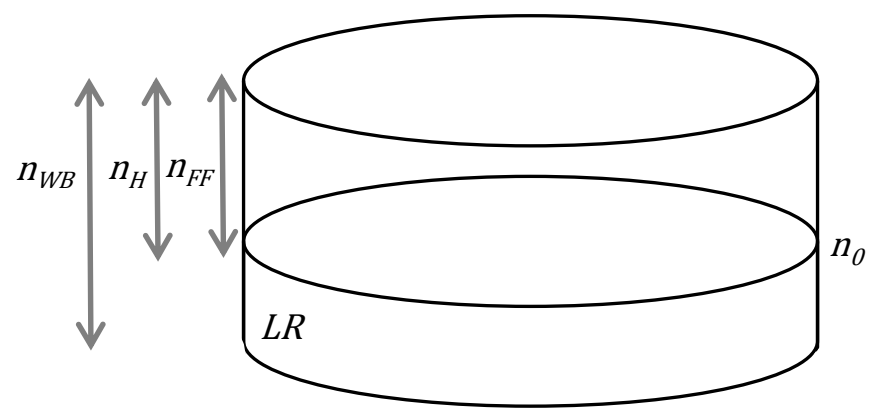

Figure 2. Range of variables $n_{W B}, n_{H}$ and $n_{F F}$.

The level $n_{0}$ is the minimum level of the lower reservoir and it is fixed at $21,400 \mathrm{~m}^{3}$ of water, equivalent of about seven days of minimum water demand forecasted for 2020. Figure 3 shows the definition of $n_{W B}$, parameter $a, n_{H}$, parameters $b$ and $n_{F F}$.

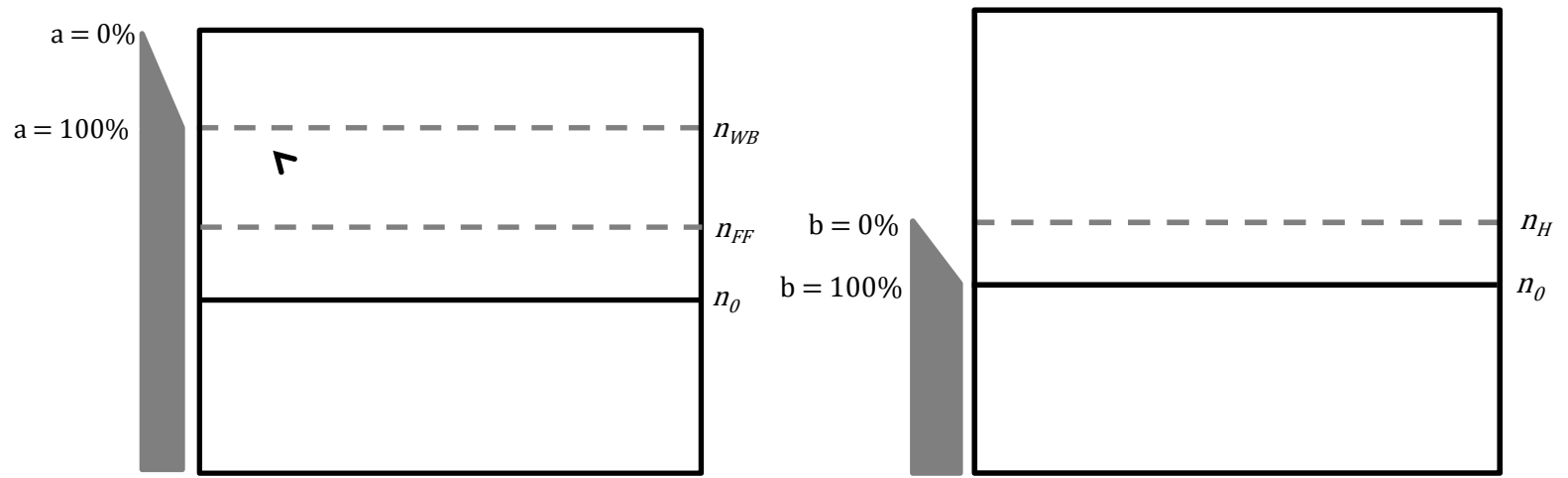

Figure 3. Definition of $n_{W B}$ and parameter $a$, and of $n_{H}$ and parameter $b$ and $n_{F F}$.

Since $n_{H}$ and $n_{F F}$ can range from $n_{0}$ to $n_{T}, f_{H}$ and $f_{F F}$ are used to determine $n_{H}$ and $n_{F F}$, respectively, as shown in Eqs. 1 and 2.

$n_{F F}=n_{0}+f_{F F}\left(L R-n_{0}\right)$ 


$$
n_{H}=n_{0}+f_{H}\left(L R-n_{0}\right)
$$

\subsubsection{Water produced from wind power}

The water produced in the desalination units is placed in the lower reservoir, with a capacity of $L R$. The amount of water produced is limited by the desalination capacity installed. When the level of the lower reservoir is between 0 and $n_{W B}$ (wind balance level), all wind power excess is used in the desalination units to produce fresh water. Only if after the desalination there is still some wind power left, it is used to pump water from the lower reservoir to the upper reservoir. When the level of the lower reservoir surpasses $n_{W B}$, a balance starts with the use of the wind power excess: $a \%$ of the wind power excess is used in the desalination units and $(1-a) \%$ is used to pump water (Figure 3). Hence, when $a$ is equal to $100 \%$ (the level of the reservoir is equal or inferior to $\left.n_{W B}\right), 100 \%$ of the wind power excess is used in the desalination units, and only what is left is used in the pumps. When $a$ is equal to 0 , all wind power excess is used in the pumps and none is used to desalinate. From $a=100 \%$ to $a=0$, the amount of wind power used to desalinate decreases and the amount of wind power used to pump increases. The equation used to determine $a$ in each hour and for each level of the lower reservoir $\left(n_{L R_{-} h}\right)$ is the following:

$a_{h}\left(n_{L R_{-} h}\right)=\left\{\begin{aligned} 1, & n_{L R_{-} h} \leq n_{W B} \times L R \\ \frac{L R-n_{L R_{-} h}}{L R-n_{W B} \times L R}, & n_{L R_{-} h}>n_{W B} \times L R\end{aligned}\right.$

The estimation of the hourly water produced from wind power, and the hourly wind power used to produce water is done using the following equations: 
$W_{W i n d \_h}=\operatorname{Min}\left(a_{h-1} \frac{E_{W_{-} P o t \_}-E_{W_{-} T a k e n \_h}}{\text { etd }} ; \frac{\text { desalcap }}{24}\right)\left(m^{3}\right)$

$E_{W_{-} D e s a l \_h}=W_{W i n d \_h} \times \operatorname{etd}(k W h)$

where desalcap is the desalination capacity installed in $m^{3} /$ day and etd is the energy needed to desalinate each unit of water in $\mathrm{kWh} / \mathrm{m}^{3}$.

\subsubsection{Water pumped}

The pumps send the water from the lower reservoir to the upper reservoir. The pumps are always in operation provided that: there is enough wind power available, there is water in the lower reservoir in the previous hour, and there is space in the upper reservoir in the previous hour (Eq. 6). As mentioned above, the wind power available to pump depends on parameter $a$ (Figure 3). Other limitation of the water pumped is, naturally, the installed pump power (Eq. 6). It is considered that the energy the pumps can provide in one hour is equal to their nominal power. Eqs. 6 and 7 are used to estimate the hourly water pumped and hourly wind power used to pump:

$$
\begin{aligned}
& W_{\text {Pump } \_}=\operatorname{Min}\left(\frac{E_{W_{-} P o t \_}-E_{W_{-} T a k e n_{-} h}-E_{W_{-} \text {Desal_h }}}{E_{\text {Pump } 1 m^{3}}} ; \frac{\text { Pump Power }}{E_{\text {Pump } 1 m^{3}}} ; n_{L R_{-} h-1} ; U R\right. \\
& \left.-n_{U R_{-} h-1}\right)\left(m^{3}\right) \\
& E_{W_{-} \text {Pump } h}=W_{\text {Pump_h }} \times E_{\text {Pump } 1 m^{3}}(k W h)
\end{aligned}
$$

where Pump Power is the power of the pumps and $U R$ is the capacity of the upper reservoir. 


\subsubsection{Water turbinated}

When the level of the lower reservoir in less or equal to $n_{0}$, the water is always being retrieved from the upper to the lower reservoir through a hydro turbine (turbinated), as long as there is water in the upper reservoir, with the limitation of the hydro turbine capacity installed. The hydro turbine operates at $b \%$ of its capacity (Figure 3, Eq. 8), hence it works at $100 \%$ when the level of the lower reservoir is $n_{0}$ or lower, and at 0 when the level of the lower reservoir reaches $n_{H}$ (level at which the hydro production stops). Other limitation of the water turbinated is the available space for water in the lower reservoir (Eq. 9). Finally, the water turbinated must not produce more electricity than the one needed to supply the undelivered hourly load after the direct supply of wind power (Eq. 9), in order to match the supply with the demand.

$$
b_{h}\left(n_{L R_{h}}\right)=\left\{\begin{aligned}
1, & 0 \leq n_{L R_{h}} \leq n_{0} \\
\frac{n_{L R_{h}}-n_{0} \times L R}{n_{H} \times L R-n_{0} \times L R}, & n_{0}<n_{L R_{h}}<n_{H} \times L R \\
0, & n_{L R_{h}} \geq n_{H} \times L R
\end{aligned}\right.
$$

Equations 9 and 10 are used to calculate the hourly water turbinated and the corresponding hydro production:

$$
\begin{aligned}
& W_{\text {Turb_h }}=\operatorname{Min}\left(\left(1-b_{h-1}\right) \frac{\text { Hydro Power }}{E_{\text {Hydro } 1 m^{3}}} ; n_{U R_{h}} ; L R-n_{L R_{h}} ; \frac{E_{\text {Und_Load_h }}}{E_{\text {Hydro } 1 m^{3}}}\right)\left(m^{3}\right) \\
& E_{\text {Hydro_h }}=W_{\text {Turb_h } h} \times E_{\text {Hydro } 1 m^{3}}(k W h)
\end{aligned}
$$


where Hydro Power is the power of the hydro turbines of the PHS system. It is considered that the energy the hydro turbines can produce in one hour is equal to their nominal power.

\subsubsection{Water produced with fossil fuel}

The fossil fuel based units are used to feed the desalination units only if the level of the lower reservoir is less than $n_{0}$ and if it is not possible to retrieve water from the upper to the lower reservoir. In this case, fossil fuel supplies the desalination units that produce water in order to increase the level of the lower reservoir until $n_{F F}$. Obviously, the desalination capacity limits this operation. It is considered that the desalination units can provide in one hour the amount of water equal to their nominal production capacity. The hourly water produced with fossil fuel and the corresponding electricity needed are calculated using the following equations:

$$
\begin{aligned}
& W_{F F_{-} h}=\operatorname{Min}\left(n_{F F} \times L R-n_{L R_{\_} h-1}-W_{T u r b \_h} ; \text { desalcap }-W_{\text {Wind } \_h}\right)\left(m^{3}\right) \\
& E_{F F_{-} W a t e r \_h}=W_{F F_{-} h} \times \text { etd }(k W h)
\end{aligned}
$$

\subsubsection{Upper and lower reservoir levels}

The level of the lower reservoir in each hour of the year (Eq. 13) is the sum of the water stored in the previous hour with the water produced (from wind power and from fossil fuel) and with the water turbinated, minus the water consumed (supplied to the population) and the water pumped.

$$
n_{L R_{-} h}=n_{L R_{-} h-1}+W_{W i n d \_h}+W_{F F_{-} h}+W_{T u r b \_h}-W_{\text {Cons } \_h}-W_{P u m p \_h}\left(m^{3}\right)
$$


The level of the upper reservoir in each hour of the year (Eq. 14) is the sum of the water stored in the previous hour with water pumped minus the water turbinated.

$n_{U R_{-} h}=n_{U R_{-} h-1}+W_{P u m p \_h}-W_{\text {Turb } \_h}\left(m^{3}\right)$

\subsubsection{Yearly values}

After the hourly calculations, the following results are summed into yearly values: wind power used to desalinate, wind power used to pump, wind power curtailed, fossil fuel used to desalinate and electricity produced in the PHS system. It is assumed that the rest of the load that is not covered by wind power and by PHS production is covered by the fossil fuel based units. In this case, the minimum load of these units is not considered, since its production is not estimated in an hourly basis. With these results it is possible to calculate the total annualized production costs of the integrated electricity and water supply system.

The total annualized production costs (Eq. 15) consider the annualized investment costs, the annual operation and management costs and fuel costs in case of electricity production and electricity costs in case of water production [8].

$T C=I C_{E} \times C R F+O M C_{E}+F C+I C_{W} \times C R F+O M C_{W}+E C(€)$

where $I C_{E}$ is the total investment cost of the energy supply system. $C R F$ is the capital recovery factor (annuity factor) that is used to annualize the investment cost and depends on the lifetime of the equipment $(n)$ and on the discount rate considered $(i)$ as follows:

$C R F=\frac{i(1+i)^{n}}{(1+i)^{n}-1}$ 
In Eq. 15, $O M C_{E}$ is the total yearly operation and management cost of the system that usually is, according to the technology, a given percentage of the investment cost. $F C$ is the yearly fossil fuel cost. $I C_{W}$ is the total investment cost of the water supply system. $O M C_{W}$ is the total yearly operation and management cost of the system. $E C$ is the yearly electricity cost, i.e. the cost of the electricity used to desalinate [8].

The investment costs consider the costs of the wind turbines $(2,000 € / \mathrm{kW})$, the fossil fuel based units $(1,200 € / \mathrm{kW})$, the desalination units $\left(1,000 € /\left(\mathrm{m}^{3} /\right.\right.$ day $\left.)\right)$ and the PHS $(500 € / \mathrm{kW}$ for the hydro turbines and the pumps and $7.5 € / \mathrm{kWh}$ for the storage). The fixed operation and maintenance $(\mathrm{O} \& \mathrm{M})$ costs are different according to the technology and its annual value is a given percentage of the total investment cost (3\% for wind turbines, $1.5 \%$ for fossil fuel based units, $10 \%$ for desalination units and $1.5 \%$ for the PHS). The PHS system also has a variable O\&M cost of about $1.5 € / M W h$ [8]. Since the PHS allows the simultaneous operation of the pumps and of the hydro turbines, it must be composed of a double penstock.

The fuel cost per kWh of electricity produced by the fossil fuel technologies is estimated based on the information on the fuel specific consumption $(\mathrm{g} / \mathrm{kWh})$ of the existing fossil fuelfired units, percentage of use of each fuel to produce electricity and the current prices of each fuel $(€ / \mathrm{kg})$ in Cabo Verde. The estimations lead to about a cost of $0.268 € / \mathrm{kWh}$ in 2020 [8]. It is important to refer that the volatile nature of the fuel costs requests for a sensitivity analysis that is done in this study. Since the fuel cost around the world has been decreasing, the estimation done was updated considering the current fuel costs in Cape Verde, and the value reached is $0.126 € / \mathrm{kWh}$, about $53 \%$ lower than in the reference case [27].

The $\mathrm{CO}_{2}$ emissions cost is also considered. The value used is the cost of the Certified Emission Reduction, whose average value since the carbon market was created until today is $6.96 € / \mathrm{tCO}_{2}[28]$ 


\subsection{Multiobjective optimization}

A constrained nonlinear multiobjective optimization problem can be written in the following form.

Find $n$ design variables:

$\boldsymbol{x}=\left(x_{1}, x_{2}, \ldots, x_{n}\right)^{T}$

which minimizes:

$$
\min _{\text {s.t. } \boldsymbol{x} \in \Omega} F(\boldsymbol{x})=\left[f_{1}(\boldsymbol{x}), f_{2}(\boldsymbol{x}), \ldots, f_{m}(\boldsymbol{x})\right]^{T}
$$

involving $m$ objective functions $f_{j}: \Omega \subseteq \mathbb{R}^{n} \rightarrow \mathbb{R} \cup\{+\infty\}, j=1, \ldots, m$ to minimize. If $m=1$ one has a single objective optimization problem, and if $m>1$ one has a multiobjective optimization problem. In the presence of $m>1$ objective functions, the minimizer of one function is not necessarily the minimizer of another. In this case, one does not have a single point that yields the "optimum point for all objectives". Instead, one has a set of points, called Pareto optimal or nondominated set. Given two points $x, y \in \Omega, x$ is said to dominate $y$, in Pareto sense, if and only if solution $x$ is strictly better than $y$ in at least one of the objectives and $x$ is not worse than $y$ in any of the objectives. A set of points in $\Omega$ is nondominated when no point in the set is dominated by another one in the set. Maximizing $f_{j}$ is equivalent to minimizing $-f_{j} . \Omega$ represents the feasible region.

Custódio et al. [29] proposed a multiobjective derivative free methodology named the Direct MultiSearch (DMS), which does not aggregate any components of the objective function. This method is inspired by the search/poll paradigm of direct-search methods of directional type from single to multiobjective optimization and uses the concept of Pareto 
dominance to maintain a list of feasible nondominated points. At each iteration, the new feasible evaluated points are added to this list and the dominated ones are removed. Successful iterations correspond then to changes in the iterate list, meaning that a new feasible nondominated point was found. Otherwise, the iteration is declared as unsuccessful. The search step is optional and when included it aims to improve numerical performance. This method was compared with eight other solvers commonly used in derivative free multiobjective optimization, for 100 multiobjective optimization problems reported in literature. The method was assessed regarding the ability to obtain points that are Pareto optimal and to compute a highly diversified subset of the whole Pareto front [29]. For the metrics considered, DMS has proved to be highly competitive with the remaining solvers [29]. A number of details are omitted and the reader is referred to [29] for a complete description.

The multiobjective optimization problem of this study is to find nine design variables, presented in Table 2 .

$\boldsymbol{x}=\left(x_{1}, \ldots, x_{9}\right)^{T}$

that simultaneously minimize the total annualized production costs of the integrated energy and water supply system $\left(f_{1}\right)$, maximize the percentage of RES production of this system $\left(f_{2}\right)$ and minimize the wind power curtailed $\left(f_{3}\right)$, which is equivalent to:

$$
\min _{\text {s.t. } x \in \Omega} F(\boldsymbol{x})=\left[f_{1}(\boldsymbol{x}),-f_{2}(\boldsymbol{x}), f_{3}(\boldsymbol{x})\right]^{T}
$$

In this case, the $\Omega$ is defined by the bound constraints of each design variable, defined in the range column of Table 2 . 
Table 2. Variables of the optimization problem, respective range and iteration step.

\begin{tabular}{|l|l|c|c|}
\hline \multicolumn{2}{|c|}{ Variable } & Range & Iteration step \\
\hline$x_{1}$ & Wind power (MW) & $6.85-28.10$ & 0.85 \\
\hline$x_{2}$ & Desalcap $\left(\mathrm{m}^{3} / \mathrm{day}\right)$ & $5,400-16,400$ & 1,000 \\
\hline$x_{3}$ & Pump power (MW) & $0.5-20$ & 0.5 \\
\hline$x_{4}$ & Hydro power (MW) & $0.5-20$ & 0.5 \\
\hline$x_{5}$ & LR $\left(\mathrm{m}^{3}\right)$ & $30,000-100,000$ & 5,000 \\
\hline$x_{6}$ & UR $\left(\mathrm{m}^{3}\right)$ & $30,000-500,000$ & 5,000 \\
\hline$x_{7}$ & $n_{W B}$ & $0.00-1.00$ & 0.01 \\
\hline$x_{8}$ & $f_{H}$ & $0.00-1.00$ & 0.01 \\
\hline$x_{9}$ & $f_{F F}$ & $0.00-1.00$ & 0.01 \\
\hline
\end{tabular}

The first six variables are related to the sizing of the integrated power and water supply system. The installed wind power (Wind power) ranges from the current wind power installed to the addition of 25 Vestas V52 turbines (with $850 \mathrm{~kW}$ of capacity); hence the iteration step of this variable is $0.85 \mathrm{MW}$. The desalination capacity installed (Desalcap) ranges from the current capacity installed to the addition of 11 desalination units of 1,000 $\mathrm{m}^{3} /$ day units. The installed pump and hydro power range between $0.5 \mathrm{MW}$ and $20 \mathrm{MW}$, their iteration step is $0.5 \mathrm{MW}$, corresponding to one unit installed of each technology. $L R$ and $U R$ are the capacity of the lower and upper reservoirs of the PHS proposed, respectively. The remaining three variables are the ones that translate the operational strategy of the proposed system.

Three penalties are added to the total annualized production costs in order to avoid solutions that would result in undelivered water to the population and overflow of the upper and lower reservoirs. 


\subsection{Criteria for selection of nondominated solutions}

As mentioned above, in multiobjective optimization, there is the Pareto dominance concept. Contrary to the case of single objective optimization, where the optimal solution is the one that gives the minimum (or maximum) value of the objective function, in multiobjective optimization the purpose is to find good compromises between the objectives to optimize, hence the notion of optimally is different. The concept of dominance lies in the fact that in these problems, among the several possible solutions, moving from one solution to another, causes an improvement for one objective function, while making the other objective function worse.

In this paper, two different processes are used to select the nondominant solutions. Firstly, the Pareto optimal set is outlined favouring the planes $f_{1}-f_{2}, f_{2}-f_{3}$ and $f_{1}-f_{3}$; and the nondominant solutions that stand out from the resulting figures are analysed.

The second process used is the normalization of the objective functions and identification of what are the best solutions for norms $L_{1}$ (Eq. 21), $L_{2}$ (Eq. 22) and $L_{\infty}$ (Eq. 23).

$\min \left(\sum_{i=1}^{3} \mathcal{A}_{i, 1}, \sum_{i=1}^{3} \mathcal{A}_{i, 2}, \ldots, \sum_{i=1}^{3} \mathcal{A}_{i, k}\right)$

$\min \left[\left(\sum_{i=1}^{3}\left(\mathcal{A}_{i, 1}\right)^{2}\right)^{1 / 2},\left(\sum_{i=1}^{3}\left(\mathcal{A}_{i, 2}\right)^{2}\right)^{1 / 2}, \ldots,\left(\sum_{i=1}^{3}\left(\mathcal{A}_{i, k}\right)^{2}\right)^{1 / 2}\right]$

$\min \left(\max _{i=1,2,3} \mathcal{A}_{i, 1}, \max _{i=1,2,3} \mathcal{A}_{i, 2}, \ldots, \max _{i=1,2,3} \mathcal{A}_{i, k}\right)$

where $\mathcal{A}_{i, j}$ is the matrix of nondominated solutions normalized, where $i(i=1,2,3)$ represents the objective functions and $j(j=1, \ldots, k)$ with $k$ the number of nondominated 
solutions. If $\mathrm{A}$ is the matrix of the nondominant solutions, matrix $\mathcal{A}_{i, j}$ is calculated using Eq. 24.

$\mathcal{A}_{i, j}=\frac{\mathrm{A}_{i, j}-\min _{j} \mathrm{~A}_{i, j}}{\max _{j} \mathrm{~A}_{i, j}-\min _{j} \mathrm{~A}_{i, j}}$

\section{Results}

Figure 5 presents the 5910 nondominated solutions (Pareto optimal set) obtained with this optimization.

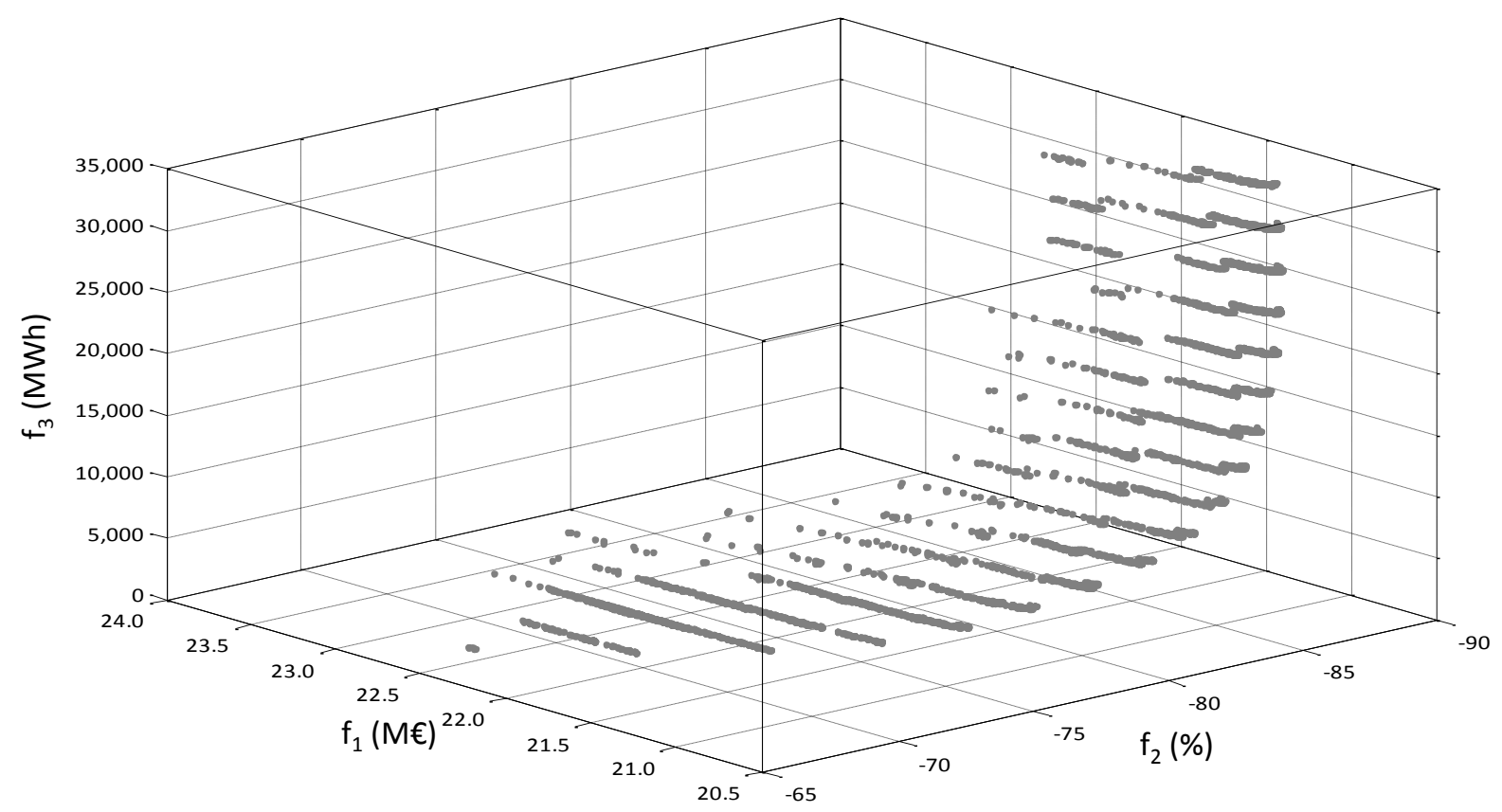

Figure 5. Pareto optimal set of the optimization problem.

\subsection{Pareto optimal set in different points of view}

To analyse these solutions in more detail, the Pareto optimal set is outlined favouring the

planes $f_{1}-f_{2}, f_{2}-f_{3}$ and $f_{1}-f_{3}$. Figure 6,7 and 8 present the three resulting graphics from these 
different points of view. In each figure, the nondominant solutions analysed are labelled from A to $\mathrm{G}$.

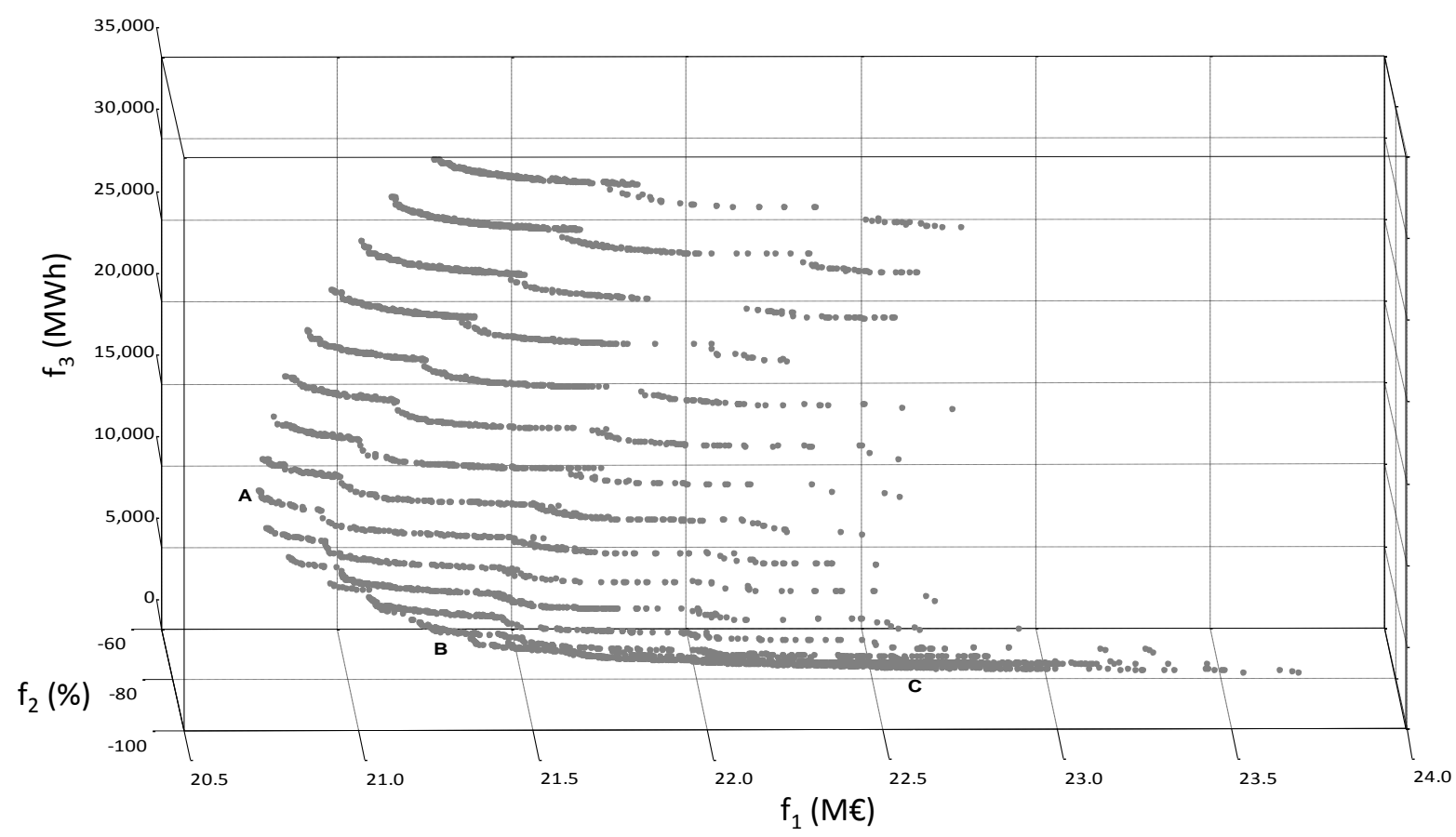

Figure 6. Pareto optimal set with the point of view favouring plane $f_{1}-f_{3}$. 


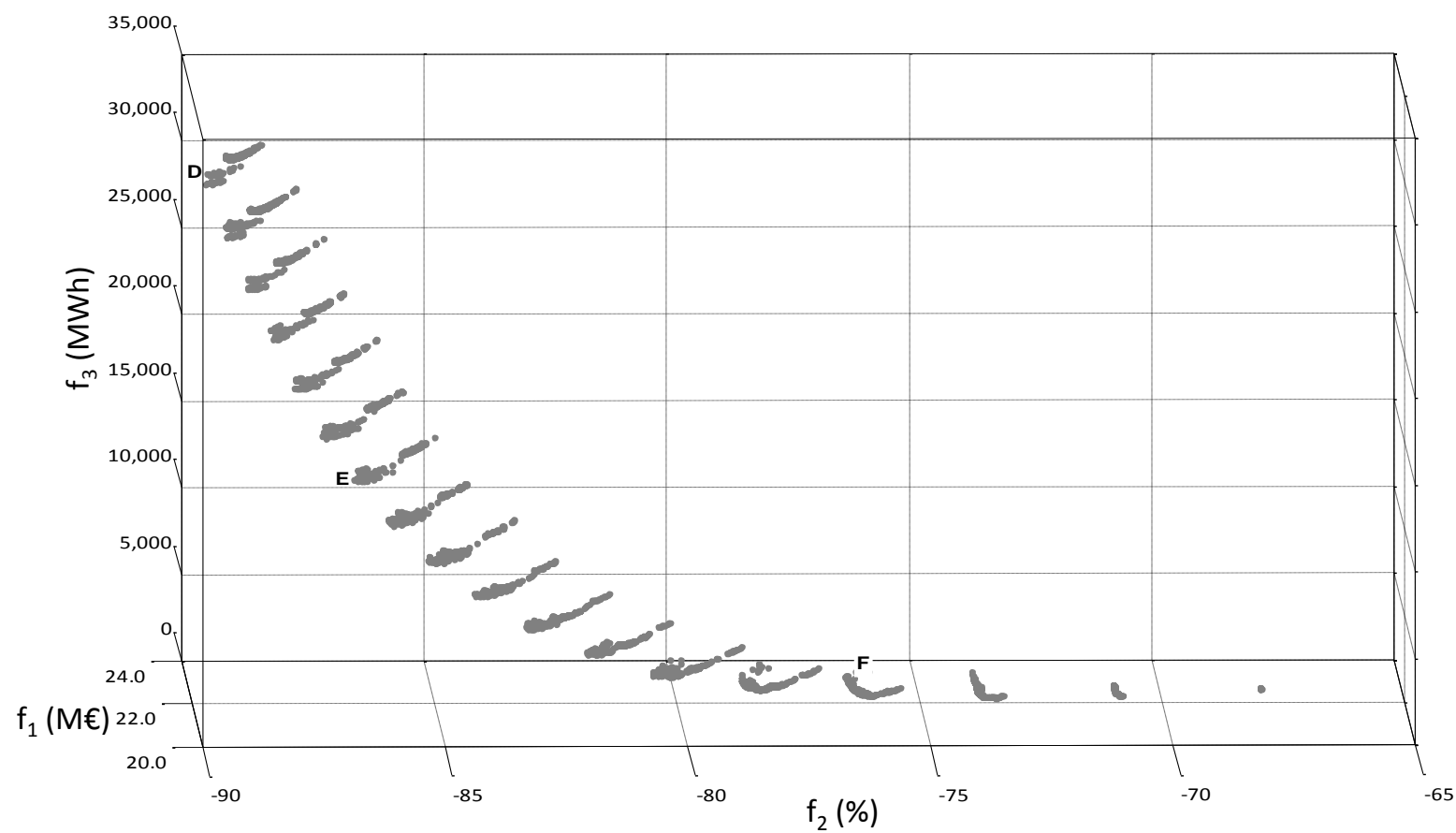

Figure 7. Pareto optimal set with the point of view favouring plane $f_{2}-f_{3}$.

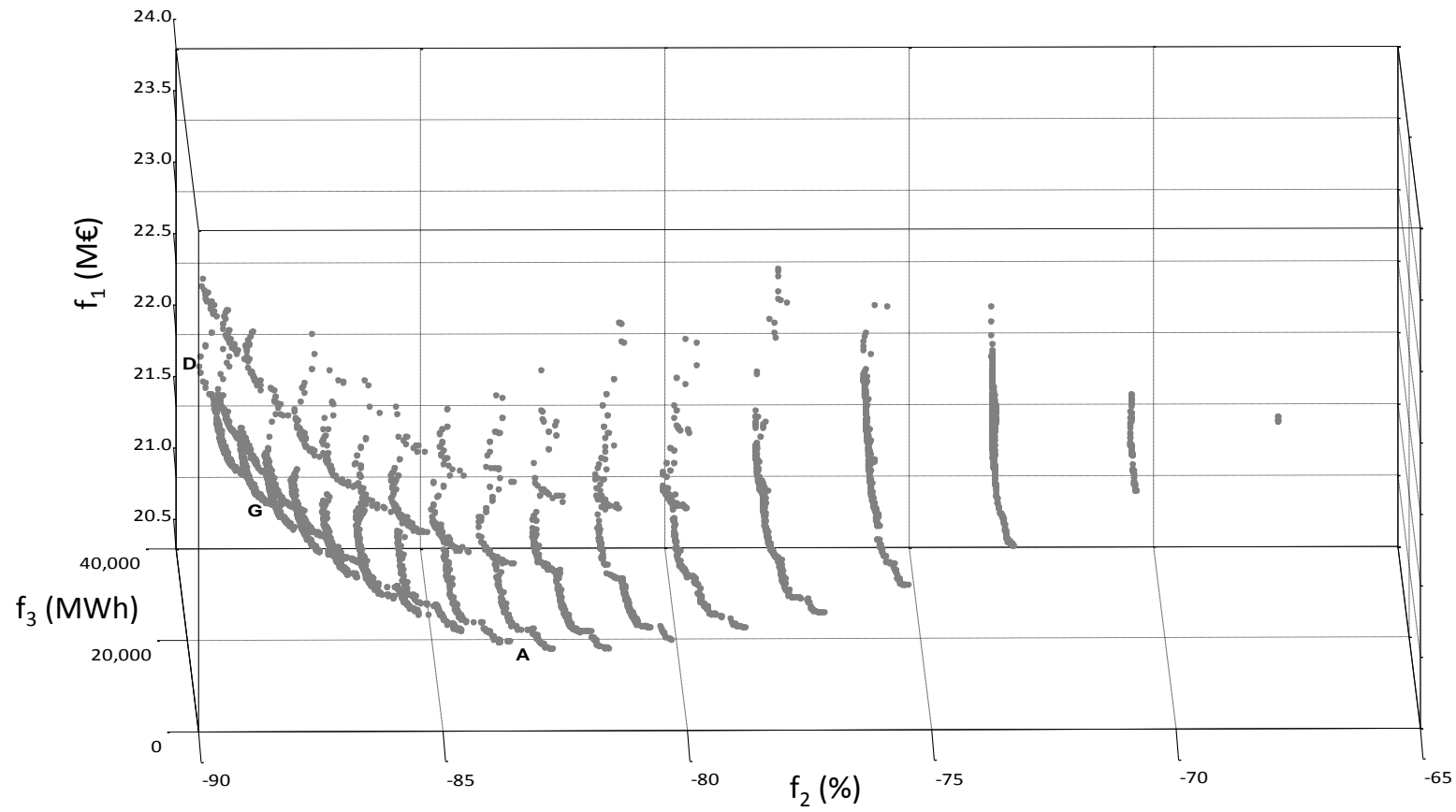

Figure 8. Pareto optimal set with the point of view favouring plane $f_{2}-f_{1}$.

The best solution for $f_{1}$ in relation to $f_{3}$, i.e. the total annualized production costs in relation to the wind power curtailed, is A, which is the solution that minimizes the total 
annualized production costs. The best solution for $f_{3}$, in relation to $f_{1}$ is $\mathrm{C}$, which is the solution that minimizes the wind power curtailed. The solution in between is B.

The best solution for $f_{2}$ in relation to $f_{3}$, i.e. the share of RES in relation to the wind power curtailed, is $\mathrm{D}$, which is the solution that maximizes the share of RES in the total power production. The best solution for $f_{3}$ in relation to $f_{2}$ is $\mathrm{F}$, which is the solution that minimizes the wind power curtailed. The solution in between is $\mathrm{E}$.

The best solution for $f_{1}$ in relation to $f_{2}$, i.e. the total annualized production cost in relation to the share of RES, is A, this is the solution that minimizes the total annualized production costs of the proposed system. The best solution for $f_{2}$ in relation to $f_{1}$ is $\mathrm{D}$, which is the solution that maximizes the share of RES in the total power production. These two solutions are already identified in the previous graphics since $\mathrm{A}$ is also the best for $f_{1}$ in relation to $f_{3}$, i.e. the total annualized production cost in relation to the wind power curtailed, and $\mathrm{D}$ is also the best for $f_{2}$ in relation to $f_{3}$, i.e. the share of RES in relation to the wind power curtailed. The solution in between is $\mathrm{G}$.

Table 3 presents the detailed results of these solutions regarding the sizing, the operational strategy and the results of the modelling for the year 2020. As the solutions go from the minimum total cost $(\mathrm{A})$ to the minimum wind power curtailed solution $(\mathrm{C})$, the installed wind power decreases, as well as the PHS systems' size. The share of RES in the power production decreases, hence the $\mathrm{CO}_{2}$ emissions increase. $n_{H}$ and $n_{F F}$ are very similar in all solutions, being its maximum and minimum value, respectively. 
Table 3. Detailed results of the nondominant solutions analysed

\begin{tabular}{|c|c|c|c|c|c|c|c|c|}
\hline \multicolumn{2}{|c|}{ Solution } & $\mathbf{A}$ & $\mathbf{B}$ & $\mathbf{C}$ & $\mathbf{D}$ & $\mathbf{E}$ & $\mathbf{F}$ & $\mathbf{G}$ \\
\hline \multirow{6}{*}{$\begin{array}{c}\text { Installed } \\
\text { equipment }\end{array}$} & $x_{1}(\mathrm{MW})$ & 21.30 & 17.05 & 13.65 & 28.10 & 23.00 & 16.20 & 27.25 \\
\hline & $x_{2}\left(\mathrm{~m}^{3} /\right.$ day $)$ & 6,400 & 7,400 & 6,400 & 7,400 & 8,400 & 11,400 & 6,400 \\
\hline & $x_{3}(\mathrm{MW})$ & 14.5 & 12.0 & 11.0 & 19.5 & 19.5 & 12.5 & 18 \\
\hline & $x_{4}(\mathrm{MW})$ & 8.5 & 8.0 & 7.5 & 19.5 & 19.0 & 19.0 & 10.0 \\
\hline & $x_{5}\left(1,000 \mathrm{~m}^{3}\right)$ & 100 & 95 & 95 & 100 & 100 & 100 & 100 \\
\hline & $x_{6}\left(1,000 \mathrm{~m}^{3}\right)$ & 150 & 165 & 75 & 280 & 340 & 340 & 170 \\
\hline \multirow{5}{*}{$\begin{array}{l}\text { Operational } \\
\text { strategy }\end{array}$} & $x_{7}$ & $77.0 \%$ & $18.0 \%$ & $61.0 \%$ & $5.0 \%$ & $5.0 \%$ & $11.0 \%$ & $21.0 \%$ \\
\hline & $x_{8}$ & $99.0 \%$ & $100 \%$ & $98.0 \%$ & $100 \%$ & $100 \%$ & $100 \%$ & $99.0 \%$ \\
\hline & $n_{H}$ & $99.2 \%$ & $100 \%$ & $98.5 \%$ & $100 \%$ & $100 \%$ & $100 \%$ & $99.2 \%$ \\
\hline & $x_{9}$ & $0.0 \%$ & $5.0 \%$ & $5.0 \%$ & $5.0 \%$ & $3.0 \%$ & $3.0 \%$ & $3.0 \%$ \\
\hline & $n_{F F}$ & $21.4 \%$ & $26.4 \%$ & $26.4 \%$ & $25.3 \%$ & $23.8 \%$ & $23.8 \%$ & $23.8 \%$ \\
\hline \multirow{3}{*}{$\begin{array}{c}\text { RES } \\
\text { production }\end{array}$} & Wind power & $58.0 \%$ & $55.0 \%$ & $49.5 \%$ & $61.4 \%$ & $59.9 \%$ & $54.4 \%$ & $60.6 \%$ \\
\hline & PHS & $25.5 \%$ & $22.7 \%$ & $18.4 \%$ & $28.2 \%$ & $26.7 \%$ & $21.8 \%$ & $27.8 \%$ \\
\hline & $f_{2}$ & $83.5 \%$ & $77.7 \%$ & $67.9 \%$ & $89.7 \%$ & $86.7 \%$ & $76.2 \%$ & $88.4 \%$ \\
\hline \multicolumn{2}{|c|}{ Wind powered desalination } & $99.6 \%$ & $99.6 \%$ & $89.4 \%$ & $99.3 \%$ & $99.4 \%$ & $99.8 \%$ & $99.4 \%$ \\
\hline \multicolumn{2}{|l|}{$f_{3}(\mathrm{MWh})$} & 12,126 & 2,203 & 0 & 30,418 & 12,964 & 0 & 29,977 \\
\hline \multicolumn{2}{|l|}{$f_{1}(\mathrm{M} €)$} & 20.74 & 21.35 & 22.66 & 22.08 & 21.96 & 23.47 & 21.17 \\
\hline \multicolumn{2}{|c|}{$\mathrm{CO}_{2}$ emissions $\left(\mathrm{ktonCO}_{2}\right)$} & 15.4 & 19.6 & 25.7 & 10.4 & 13.0 & 20.7 & 11.5 \\
\hline
\end{tabular}

As the solutions go from the maximum percentage of RES solution (D) to the minimum wind power curtailed solution $(\mathrm{F})$, the installed wind power decreases, as in the previous analysis. But in this case, the installed wind power reaches higher values; this is because the most important objective functions are the percentage of RES and the wind power curtailed and not the total annualized production costs, as in the previous analysis. The installed 
desalination capacity increases, as well as the percentage of wind powered desalination, although slightly. The total annualized production costs also increase. In this case, the operational strategy is similar for all solutions, with $n_{H}$ and $n_{F F}$ at its maximum and minimum value, respectively.

As the solutions go from the minimum total cost solution (A) to the maximum percentage of RES solution (D), the size of the proposed system increases in terms of installed power and size of the upper reservoir. The size of the lower reservoir $\left(x_{5}\right)$ does not increase because this is already the maximum capacity allowed. The installed wind power in solution D is the maximum allowed. The share of RES production increases due to the increase of both wind power and PHS contribution to the total power production. The share of wind powered desalination decreases slightly, but is always almost 100\%. Regarding the operational strategy, $n_{H}$ and $n_{F F}$ are practically the same, being at its maximum and minimum value, respectively. $n_{W B}\left(x_{7}\right)$ decreases significantly from solution $\mathrm{A}$ to solution $\mathrm{D}$, this together with the increase of the size of the PHS system allows more water to be pumped from the lower to the upper reservoir.

Considering all the nondominated solutions of this optimization problem, the solution that minimizes the total annualized production cost $\left(f_{1}\right)$ is solution $\mathrm{A}$, that is the same that minimizes $f_{1}$ in relation to $f_{2}$ and in relation to $f_{3}$. The solution that maximizes the share of RES in total power production $\left(f_{2}\right)$ is solution $\mathrm{D}$, that is the same that minimizes $f_{2}$ in relation to $f_{1}$ and in relation to $f_{3}$. Regarding the minimization of the wind power curtailed, there are 26 solutions where this value is zero, one is solution $\mathrm{F}$ that minimizes $f_{3}$ in relation to $f_{2}$, and another is solution $\mathrm{C}$ that minimizes $f_{3}$ in relation to $f_{1}$. 


\subsection{Normalized Pareto optimal set}

Table 4 presents the detailed results regarding the sizing, the operational strategy and the results of the modelling for the year 2020 of the normalization of the objective functions and the identification of what are the best solutions for norms $L_{1}, L_{2}$ and $L_{\infty}$. The solutions identified do not differ very much from each other, as well as the corresponding results.

Table 4. Results of the solutions analysed with the normalization of the objective functions

\begin{tabular}{|c|c|c|c|c|}
\hline \multicolumn{2}{|c|}{ Solution } & Norm $L_{1}$ & Norm $L_{2}$ & Norm $L_{\infty}$ \\
\hline \multirow{6}{*}{$\begin{array}{c}\text { Installed } \\
\text { equipment }\end{array}$} & $x_{1}(\mathrm{MW})$ & 20.45 & 20.45 & 20.45 \\
\hline & $x_{2}\left(\mathrm{~m}^{3} /\right.$ day $)$ & 7,400 & 7,400 & 8,400 \\
\hline & $x_{3}(\mathrm{MW})$ & 15.0 & 16.0 & 15.0 \\
\hline & $x_{4}(\mathrm{MW})$ & 11.0 & 11.0 & 16.5 \\
\hline & $x_{5}\left(1,000 \mathrm{~m}^{3}\right)$ & 100 & 100 & 100 \\
\hline & $x_{6}\left(1,000 \mathrm{~m}^{3}\right)$ & 205 & 205 & 250 \\
\hline \multirow{5}{*}{$\begin{array}{c}\text { Operational } \\
\text { strategy }\end{array}$} & $x_{7}$ & $7.0 \%$ & $7.0 \%$ & $5.0 \%$ \\
\hline & $x_{8}$ & $100 \%$ & $100 \%$ & $100 \%$ \\
\hline & $n_{H}$ & $100 \%$ & $100 \%$ & $100 \%$ \\
\hline & $x_{9}$ & $12.0 \%$ & $6.0 \%$ & $3.0 \%$ \\
\hline & $n_{F F}$ & $30.8 \%$ & $26.1 \%$ & $23.8 \%$ \\
\hline \multirow{3}{*}{$\begin{array}{c}\text { RES } \\
\text { production }\end{array}$} & Wind power & $58.0 \%$ & $58.1 \%$ & $58.4 \%$ \\
\hline & PHS & $25.5 \%$ & $25.5 \%$ & $25.6 \%$ \\
\hline & $f_{2}$ & $83.5 \%$ & $83.6 \%$ & $83.9 \%$ \\
\hline \multicolumn{2}{|c|}{ Wind powered desalination } & $99.5 \%$ & $99.5 \%$ & $99.6 \%$ \\
\hline \multicolumn{2}{|l|}{$f_{3}(\mathrm{MWh})$} & 8,089 & 7,979 & 6,9440 \\
\hline \multicolumn{2}{|l|}{$f_{1}(\mathrm{M} €)$} & 20.98 & 21.02 & 21.51 \\
\hline \multicolumn{2}{|c|}{$\mathrm{CO}_{2}$ emissions $\left(\mathrm{ktonCO}_{2}\right)$} & 15.4 & 15.4 & 15.1 \\
\hline
\end{tabular}




\subsection{Sensitivity analysis}

A new Pareto optimal set is obtained for a fuel cost of about $0,126 € / \mathrm{kWh}$, about $53 \%$ lower than the one considered for the reference case. Table 5 presents the results of the solutions that minimize the total cost (A'), that maximizes the percentage of RES in the total power production (D') and the best solutions for norms $L_{1}, L_{2}$ and $L_{\infty}$. As expected, the size of the optimized integrated power and water supply system is much lower than in the reference case.

Table 5. Results of the solutions A', D' and norms $L_{1}, L_{2}$ and $L_{\infty}$.

\begin{tabular}{|c|c|c|c|c|c|c|}
\hline \multicolumn{2}{|c|}{ Solution } & $\mathbf{A}^{\prime}$ & D' & Norm $L_{1}$ & Norm $L_{2}$ & $\operatorname{Norm} L_{\infty}$ \\
\hline \multirow{6}{*}{$\begin{array}{c}\text { Installed } \\
\text { equipment }\end{array}$} & $x_{1}(\mathrm{MW})$ & 14.50 & 28.10 & 17.05 & 19.60 & 20.45 \\
\hline & $x_{2}\left(\mathrm{~m}^{3} /\right.$ day $)$ & 6,400 & 7,400 & 6,400 & 7,400 & 7,400 \\
\hline & $x_{3}(\mathrm{MW})$ & 11.0 & 19,5 & 12.5 & 14.5 & 16.0 \\
\hline & $x_{4}(\mathrm{MW})$ & 7.5 & 19,5 & 8.5 & 10.0 & 12.5 \\
\hline & $x_{5}\left(1,000 \mathrm{~m}^{3}\right)$ & 55 & 100 & 100 & 100 & 100 \\
\hline & $x_{6}\left(1,000 \mathrm{~m}^{3}\right)$ & 105 & 280 & 120 & 195 & 230 \\
\hline \multirow{5}{*}{$\begin{array}{c}\text { Operational } \\
\text { strategy }\end{array}$} & $x_{7}$ & $94.0 \%$ & $5.0 \%$ & $94.0 \%$ & $5.0 \%$ & $26.0 \%$ \\
\hline & $x_{8}$ & $99.0 \%$ & $100 \%$ & $99.0 \%$ & $98.0 \%$ & $100 \%$ \\
\hline & $n_{H}$ & $99.4 \%$ & $100 \%$ & $99.2 \%$ & $98.4 \%$ & $100 \%$ \\
\hline & $x_{9}$ & $1.0 \%$ & $5.0 \%$ & $8.0 \%$ & $2.0 \%$ & $12.0 \%$ \\
\hline & $n_{F F}$ & $39.5 \%$ & $25.3 \%$ & $27.7 \%$ & $23.0 \%$ & $30.8 \%$ \\
\hline \multirow{3}{*}{$\begin{array}{c}\text { RES } \\
\text { production }\end{array}$} & Wind power & $51.1 \%$ & $61.4 \%$ & $54.7 \%$ & $57.4 \%$ & $58.1 \%$ \\
\hline & PHS & $19.6 \%$ & $28.2 \%$ & $22.7 \%$ & $24.9 \%$ & $25.5 \%$ \\
\hline & $f_{2}$ & $70.7 \%$ & $89.7 \%$ & $77.4 \%$ & $82.3 \%$ & $83.7 \%$ \\
\hline \multicolumn{2}{|c|}{ Wind powered desalination } & $91.9 \%$ & $99.3 \%$ & $96.3 \%$ & $99.6 \%$ & $99.5 \%$ \\
\hline \multicolumn{2}{|l|}{$f_{3}(\mathrm{MWh})$} & 339 & 30,418 & 2,657 & 6,345 & 7,741 \\
\hline \multicolumn{2}{|l|}{$f_{1}(\mathrm{M} €)$} & 16.61 & 19.71 & 16.71 & 17.28 & 17.62 \\
\hline \multicolumn{2}{|c|}{$\mathrm{CO}_{2}$ emissions $\left(\mathrm{ktonCO}_{2}\right)$} & 24.0 & 10.4 & 19.8 & 16.3 & 15.3 \\
\hline
\end{tabular}


Although the decrease in fuel cost decreases the total costs of the Baseline Scenario significantly in relation to the reference case (17.563.202€), some of the solutions above are still able to decrease the total costs of the power and water supply in S. Vicente. Solution A' results in a $5 \%$ decrease in costs in relation to the Baseline Scenario.

\section{Discussion}

The optimization carried out for the sizing and the operational strategy of the proposed integrated system for power and water supply resulted in several solutions. For decision makers, the most relevant point of view of the Pareto optimal set is the one that favours the plane $f_{1}-f_{2}$, i.e. the plane total annualized production cost vs. share of RES. The overall solution that minimizes the total annualized production costs is solution $\mathrm{A}$ and the overall solution that maximizes the share of RES in the total power production is solution D. Table 6 presents the results of these solutions and the best solutions for norms $L_{1}, L_{2}$ and $L_{\infty}$ together with the baseline scenario foreseen for 2020. The baseline scenario considers the system installed in S. Vicente and the forecasted electricity and water consumption for 2020. The costs of this scenario also consider the $\mathrm{CO}_{2}$ emissions cost of $6.96 €$ /tonCO $\mathrm{CO}_{2}$. Table 6 presents the wind power curtailed as well as the percentage of this wind power curtailed in relation to the total wind power production potential. 
Table 6. Results of the solutions A, D and norms $L_{1}, L_{2}$ and $L_{\infty}$.

\begin{tabular}{|c|c|c|c|c|c|c|c|}
\hline \multicolumn{2}{|c|}{ Solution } & $\mathbf{A}$ & $\mathbf{D}$ & Norm $L_{1}$ & Norm $L_{2}$ & Norm $L_{\infty}$ & Baseline \\
\hline \multirow{6}{*}{$\begin{array}{c}\text { Installed } \\
\text { equipment }\end{array}$} & $x_{1}(\mathrm{MW})$ & 21.30 & 28.10 & 20.45 & 20.45 & 20.45 & 6.85 \\
\hline & $x_{2}\left(\mathrm{~m}^{3} /\right.$ day $)$ & 6,400 & 7,400 & 7,400 & 7,400 & 8,400 & 5,400 \\
\hline & $x_{3}(\mathrm{MW})$ & 14.5 & 19.5 & 15.0 & 16.0 & 15.0 & - \\
\hline & $x_{4}(\mathrm{MW})$ & 8.5 & 19.5 & 11.0 & 11.0 & 16.5 & - \\
\hline & $x_{5}\left(1,000 \mathrm{~m}^{3}\right)$ & 100 & 100 & 100 & 100 & 100 & 14,980 \\
\hline & $x_{6}\left(1,000 \mathrm{~m}^{3}\right)$ & 150 & 280 & 205 & 205 & 250 & - \\
\hline \multirow{5}{*}{$\begin{array}{c}\text { Operational } \\
\text { strategy }\end{array}$} & $x_{7}$ & $77.0 \%$ & $5.0 \%$ & $7.0 \%$ & $7.0 \%$ & $5.0 \%$ & - \\
\hline & $x_{8}$ & $99.0 \%$ & $100 \%$ & $100 \%$ & $100 \%$ & $100 \%$ & - \\
\hline & $n_{H}$ & $99.2 \%$ & $100 \%$ & $100 \%$ & $100 \%$ & $100 \%$ & - \\
\hline & $x_{9}$ & $0.0 \%$ & $5.0 \%$ & $12.0 \%$ & $6.0 \%$ & $3.0 \%$ & - \\
\hline & $n_{F F}$ & $21.4 \%$ & $25.3 \%$ & $30.8 \%$ & $26.1 \%$ & $23.8 \%$ & - \\
\hline \multicolumn{2}{|l|}{$f_{2}$} & $83.5 \%$ & $89.7 \%$ & $83.5 \%$ & $83.6 \%$ & $83.9 \%$ & $21.4 \%$ \\
\hline \multicolumn{2}{|l|}{$f_{3}(\mathrm{MWh})$} & 12,126 & 30,418 & 8,089 & 7,979 & 6,9440 & 10,898 \\
\hline \multicolumn{2}{|c|}{ Wind powered curtailed } & $12.9 \%$ & $24.5 \%$ & $9.0 \%$ & $8.8 \%$ & $7.7 \%$ & $36.5 \%$ \\
\hline \multicolumn{2}{|l|}{$f_{1}(\mathrm{M} €)$} & 20.74 & 22.08 & 20.98 & 21.02 & 21.51 & 28.40 \\
\hline \multicolumn{2}{|c|}{$\mathrm{CO}_{2}$ emissions $\left(\mathrm{ktonCO}_{2}\right)$} & 15.4 & 10.4 & 15.4 & 15.4 & 15.1 & 45.9 \\
\hline
\end{tabular}

All solutions of the optimization problem analysed present significant reduction in total annualized production costs, increase of share of RES in total power production and $\mathrm{CO}_{2}$ emissions reduction in comparison with the baseline scenario. Naturally, solution A presents the greatest savings regarding costs and solution D presents the greatest increase in the share of RES and decrease in $\mathrm{CO}_{2}$ emissions. Norms $L_{1}, L_{2}$ and $L_{\infty}$ present solutions in between $\mathrm{A}$ and $\mathrm{D}$ regarding total costs, share of RES and $\mathrm{CO}_{2}$ emissions. 
The adoption of the proposed integrated system can reduce the total annualized production costs by $22 \%$ to $27 \%$ in 2020 , increase the share of RES four times and reduce the $\mathrm{CO}_{2}$ emissions between $67 \%$ and $77 \%$. Although the wind power curtailed absolute value increases in the proposed solution, it decreases significantly in relation to the wind power production potential.

It is important to refer that the optimal capacity of the lower reservoir in these solutions is the maximum of the range considered for this variable. Despite this, this range is not increased because this capacity is considered the maximum suitable to construct in this island. Regarding the solution that maximizes the share of RES production, the same occurs for the wind power installed. A wind power of $28.10 \mathrm{MW}$ is the equivalent of installing 25 more V52 wind turbines than the ones already installed on S. Vicente. Hence, the range of this variable is also not increased.

As mentioned above, the method used to determine the contribution of the fossil fuel based units for the production of power and water in the modelling carried out for this optimization, does not take into account the minimum load of these units. However it is possible to determine the error resulting from this approximation. In each hour of the year, the electricity needed from the fossil fuel based units is determined, if it is less than its minimum load, than there is an error. The error is the amount of wind power and/or PHS production that would need to be subtracted to avoid the operation of the fossil fuel based units in levels below its minimum value. The values reached for this error are always between $1 \%$ and $5 \%$.

From the sensitivity analysis it is shown that even with a significant decrease of fuel cost, the proposed system is more economically viable than the current one installed in S. Vicente, with the advantage of being more environmentally friendly since its yields lower $\mathrm{CO}_{2}$ emissions. 


\section{Conclusions}

An optimization analysis is carried out applying the Direct MultiSearch method for the sizing and operational strategy of the proposed integrated system. The solutions of the Pareto optimal set are presented and analysed. From a purely mathematical perspective, all nondominant solutions are equivalent. Naturally, from a practical point of view, these are different. In this study, two different analyses of the results are carried out. On one hand the nondominant solutions are presented from the perspective that favours each plane composed by two objective functions. From this analysis, the decision maker needs only to decide which objective function is more important. On the other hand, in order to facilitate decision making, an analysis is done also considering the normalization of the objective functions, and a solution is chosen without having to select which objective function is more important.

With these results, the decision maker has now information regarding the optimal configuration and optimal operational strategy of the proposed integrated power and water supply system for the Island of S. Vicente

If the decision maker considers that the most important objective function is the minimization of the total annualized production costs of the integrated power and water supply system, the configuration to installed and the operational strategy to follow is able to achieve a RES production of $84 \%$ (58\% wind power and $26 \%$ PHS), with $99.6 \%$ of wind powered desalinated water, with about $27 \%$ decrease of costs in relation to those predicted for 2020. This configuration avoids about $67 \%$ of $\mathrm{CO}_{2}$ emissions forecasted for 2020 .

The optimal operational strategy of this integrated system depends greatly on the sizing of the system installed. Considering the results of the optimization analysis regarding the minimization of the costs, the optimal operational strategy consists in only producing water from the fossil fuel based units when the lower reservoir has less water that it minimum allowed, producing electricity from the hydro plant as long as there is water in the upper 
reservoir and space for water in the lower reservoir and, finally, balancing the wind power that goes to the desalination units and to the pumps from about $77 \%$ of capacity of the lower reservoir.

As expected, the decrease of fuel costs results in a smaller optimal integrated system. However, even with a significant decrease of fuel cost, the proposed system is more economically viable than the current one installed in S. Vicente, with the advantages of being more environmentally friendly since it produces lower $\mathrm{CO}_{2}$ emissions, using mostly endogenous resources and less subjected to fossil fuel cost oscillations that are difficult to predict.

\section{Acknowledgements}

This work was supported by Fundação para a Ciência e a Tecnologia (FCT), through IDMEC, under LAETA, project UID/EMS/50022/2013. R. Segurado is pleased to acknowledge the FCT for the provision of the scholarship SFRH/BD/31663/2006.

The authors would like to thank the reviewers for their thorough examination and extremely valuable comments to this manuscript, which have undoubtedly contributed to improve considerably the quality of the work reported. 


\section{References}

[1] Papathanassiou SA, Boulaxis NG. Power limitations and energy yield evaluation for wind farms operating in island systems. Renewable Energy 2006;31:457-479.

[2] Weisser D, Garcia R. Instantaneous wind energy penetration in isolated electricity grids: concept and review. Renewable Energy 2005;30:1299-1308.

[3] Erdinc O, Paterakis NG, Catalão JPS. Overview of insular power systems under increasing penetration of renewable energy sources: Opportunities and challenges. Renewable and Sustainable Energy Reviews 2015;52:333-346.

[4] Kaldellis JK, Kapsali M, Kavadias KA. Energy balance analysis of wind-based pumped hydro storage systems in remote island electrical networks. Applied Energy 2010;87:2427-2437.

[5] Kapsali M, Kaldellis JK. Combining hydro and variable wind power generation by means of pumped-storage under economically viable terms. Applied Energy 2010;87:3475-3485.

[6] Katsaprakakis DA. Hybrid power plants in non-interconnected insular systems. Applied Energy 2016;164:268-283.

[7] Zhao H, Wu Q, Hu S, Xu H, Rasmussen CN. Review of energy storage system for wind power integration support. Applied Energy 2015;137:545-553.

[8] Segurado R, Costa M, Duić N, Carvalho MG. Integrated analysis of energy and water supply in islands. Case study of S. Vicente , Cape Verde. Energy 2015;92(3):639-648.

[9] Spyrou ID, Anagnostopoulos JS. Design study of a stand-alone desalination system powered by renewable energy sources and a pumped storage unit. Desalination 2010;257(1-3):137-149. 
[10] Corsini A, Rispoli F, Gamberale M, Tortora E. Assessment of H2- and H2O-based renewable energy-buffering systems in minor islands. Renewable Energy 2009;34(1):279-288.

[11] Henderson CR, Manwell JF, McGowan JG. A wind/diesel hybrid system with desalination for Star Island, NH: feasibility study results. Desalination 2009;237(13):318-329.

[12] Setiawan AA, Zhao Y, Nayar CV. Design, economic analysis and environmental considerations of mini-grid hybrid power system with reverse osmosis desalination plant for remote areas. Renewable Energy 2009;34(2):374-383.

[13] Novosel T, Cosić B, Krajač ić G, Duić N, Puksec T, Mohsen MS, Ashhab MS, Ababneh AK. The influence of reverse osmosis desalination in a combination with pump storage on the penetration of wind and PV energy: A case study for Jordan. Energy 2014;76:73-81.

[14] Østergaard PA, Lund H, Mathiesen BV. Energy system impacts of desalination in Jordan. International Journal of Sustainable Energy Planning and Management 2014;01:29-40.

[15] Santhosh A, Farid AM, Youcef-Toumi K. Real-time economic dispatch for the supply side of the energy-water nexus. Applied Energy 2014;122:42-52.

[16] Bognar K, Pohl R, Behrendt F. Seawater reverse osmosis (SWRO) as deferrable load in micro grids. Desalination and Water Treatment 2012;51(4-6):1190-1199.

[17] Baños R, Manzano-Agugliaro F, Montoya FG, Gila C, Alcayde A, Gomez J. Optimization methods applied to renewable and sustainable energy: A review. Renewable and Sustainable Energy Reviews 2011;15:1753-1766.

[18] Østergaard PA. Reviewing optimisation criteria for energy systems analyses of renewable energy integration. Energy 2009;34(9):1236-1245. 
[19] Petruschke P, Gasparovic G, Voll P, Krajač ić G, Duić N, Bardow A. A hybrid approach for the efficient synthesis of renewable energy systems. Applied Energy 2014;135:625-633.

[20] Zhou W, Lou C, Li Z, Lu L, Yang H. Current status of research on optimum sizing of stand-alone hybrid solar-wind power generation systems. Applied Energy 2010;87(2):380-389.

[21] Anagnostopoulos JS, Papantonis DE. Simulation and size optimization of a pumpedstorage power plant for the recovery of wind-farms rejected energy. Renewable Energy 2008;33:1685-1694.

[22] Ren H, Zhou W, Nakagami K, Gao W, Wu Q. Multi-objective optimization for the operation of distributed energy systems considering economic and environmental aspects. Applied Energy 2010;87(12):3642-3651.

[23] Sharafi M, EIMekkawy T. A dynamic MOPSO algorithm for multiobjective optimal design of hybrid renewable energy systems. International Journal of Energy Research 2014;88:1949-1963

[24] Perera ATD, Attalage RA, Perera KKCK, Dassanayake. Designing standalone hybrid energy systems minimizing initial investment, life cycle cost and pollutant emission. Energy 2013;54:220-230.

[25] Ma T, Yang H, Lu L, Peng J. Pumped storage-based standalone photovoltaic power generation system: Modeling and techno-economic optimization. Applied Energy 2015;137:649-659.

[26] Segurado R, Krajač ić G, Duić N, Alves L. Increasing the penetration of renewable energy resources in S. Vicente, Cape Verde. Applied Energy 2011;88(2):466-472.

[27] Economic Regulatory Agency of Cape Verde: http://www.are.cv. Accessed on February $24^{\text {th }} 2015$. 
[28] Carbon Dioxide Emission Allowances Electronic Trading System - SENDECO2 http://www.sendeco2.com, accessed on 18th February 2015.

[29] Custódio AL, Madeira JFA, Vaz AIF and Vicente LN. Direct Multisearch for Multiobjective Optimization. SIAM Journal on Optimization 2011;21(3):1109-1140. 